\title{
Capability level of teachers of district of Sta. Teresita for school-based disaster preparedness: Basis for proposed action plan
}

Dimaculangan, Joel

Saimsim Elementary School, Philippines (joeldimaculangan611@gmail.com)

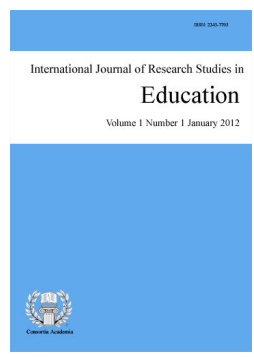

ISSN: $2243-7703$ Online ISSN: 2243-7711

Received: 30 March 2021

Revised: 17 May 2021

Accepted: 10 June 2021

OPEN ACCESS

\section{Abstract}

Disaster management is one important planning, responsibility and action to be considered not only by students but even teachers. In relation to the Philippine schools' vulnerability to disasters, the study intends to evaluate capability level of the teachers of Sta. Teresita District as regards their preparedness for school-based disaster. It is needed to be understood more by the teachers for them to execute it well and even on how teachers would address different calamities and hazard that may happen in school and community. Based on the foregoing findings, the following conclusions were drawn: Majority of the respondents have attended limited number of first aid trainings and simulation exercises relative to disaster preparedness. Teachers are highly capable of preparing for natural disasters but moderately capable for human induced disasters. This paper primarily suggests the conduct of similar study to include respondents from other locales. That way, a clearer view of the capability levels for preparedness for educators may be established. Furthermore, the nature of this study might even be replicated among other schools in the different cities and municipalities of the country.

Keywords: disaster, natural hazard, human-induced hazard, capability level, teacher 


\section{A Capability level of teachers of district of Sta. Teresita for school-based disaster preparedness: Basis for proposed action plan}

\section{Introduction}

Dramatic increases have been witnessed in recent years in the frequency and impact of the hazardous natural disasters in the world. While one of the reasons for that increase may stem from the wrong use of nature and the environment by the people such as destruction of the forests, agricultural areas, freshwater sources, and the like which causes a lot of floods, fires, storms, and similar kind of disasters; the other stems from the inherent nature of the earth which produces lots of quakes, volcano explosions and the like. Whatever the reason, the truth is that lots of losses, injuries, and damages have been experienced during these disasters, and by training the people the rate of the losses and damages may be lessened and even in some cases may entirely be prevented. For that reason, especially by UN agencies and by some developed countries, some efforts are devoted to the training of people by awakening them towards disasters and by training them about what they will do before, during, and after the occurrence of the disasters.

The US Economic Development Administration (2016) enumerated the two most common types of disaster: natural and man-made. Natural disasters are caused by natural events and may originate from geographical and hydro-meteorological means. Common examples include earthquakes, landslides, volcanic eruptions, tsunamis, tropical cyclones, thunderstorms, flooding, and drought (Fact Monster, 2015). Man-made disasters, on the other hand, are caused by human activities either by intention or by negligence. These include fires, chemical spills, groundwater contamination, social violence, and political unrest.

The Department of Education (DepEd) of the Philippines is one of the agencies of the government which play an important role in disaster risk reduction and management. This is primarily evidenced by the inclusion of DepEd in the National Disaster Risk Reduction and Management Council as mandated by the Philippine Disaster Risk Reduction and Management Act of 2010. This sector of the government likewise recognizes its part in disaster management as it continually makes an effort to ensure the safety of both the students and the teachers in schools about the possible occurrences of disasters (Department of Education, 2015). Then- the secretary of DepEd Jesli Lapus has reiterated that saving human life and property is a challenge for the public and private sectors. DepEd, in its provision of quality basic education, is also responsible for ensuring safe school facilities and a risk-free school environment for Filipino children (Disaster Risk Reduction Resource Manual, 2008).

Despite the continuous efforts of the Department of Education in mainstreaming disaster risk reduction and management in public elementary and high schools in the Philippines, schools in the country continue to become critical infrastructures vulnerable to disasters. Berse (2015) said that schools and Filipino children are prone to disasters. Common effects of disasters in schools include massive flooding, roof tearing and structural damages due to strong winds. The researcher, being a teacher in public school, taught students about Disaster management as a part of the curriculum. Disaster management is one important planning, responsibility and action to be considered not only by students but even teachers. As mentioned, Disasters may be classified as Natural and Anthropogenic, or Human-Induced disasters and that disaster may happen without prior notice. It is why this present study is being conducted to be able to know the capability of teachers in handling and taking actions in different disasters that we do not expect to happen. The researcher witnessed that this was newly included in the curriculum and there were some terminologies and topics that were intended to be taught to the learners. It is needed to be understood more by the teachers for them to execute it well and even on how teachers would address different calamities and hazards that may happen in school and community. This study aims to determine how prepared the teachers are in terms of the preparation before, during, and after a certain hazard. Likewise, not only the school will benefit if teachers are capable of handling this kind of situation but also the community

94 Consortia Academia Publishing (A partner of Network of Professional Researchers and Educators) 
as well.

\subsection{Theoretical framework}

This study is anchored on the Association of Southeast Asian Nations (ASEAN) Common Framework for Comprehensive School Safety (ACFCSS) developed by the ASEAN Safe Schools Initiative (2015), to operationalize and contextualize the globally recognized Comprehensive Safe School Framework in the region. The Framework is intended to provide a conceptual basis of concerned agencies in the region, Ministries of Education and National Disaster Management Agencies, in particular, to develop school safety interventions based on country-specific need and context, as well as guide the Member States on the operationalization of the framework to effectively translate the concept into concrete actions with substantive impacts. The goals of the framework are to secure the safety and security of children in school from the impacts of all types of hazards, to ensure education continuity, and to uphold children's rights to quality basic education, including anticipation and mitigation of the impacts of known and expected hazards.

The need for a child-centered multi-hazard risk assessment as the starting point for understanding the scope of needs is recognized, though not yet systematically approached. The value of engaging the different stakeholders and agencies needed to take action on each of the three pillars of Comprehensive School Safety is also widely recognized among development partners and education authorities in ASEAN countries. This has become a common reference for discussions on the initiatives of integrating disaster risk reduction options and practices into the education sector. Some countries have adopted, adapted, and are actively using the framework as a model to guide planning and programming on safe schools. Countries like Cambodia, the Philippines, Thailand, and Lao PDR have also referred to the CSS Framework in their school safety programming. The Philippines indicates in its Hyogo Framework for Action (HFA) Progress Report 2013-2015, that the Comprehensive School Safety Framework is operationalized based on the three pillars, provides the foundation for the DRRM in Basic Education together with the four DDRM elements (recovery \& rehabilitation, response, preparedness, prevention \& mitigation). This is also in consonance with the 2011-2018 National Disaster Risk Reduction and Management (NDRRM) Framework (Philippines National Progress Report on the Implementation of the Hyogo Framework for Action 2013- 2015).

\subsection{Conceptual framework}

The relationship of the variables in this study is presented in the research framework below.

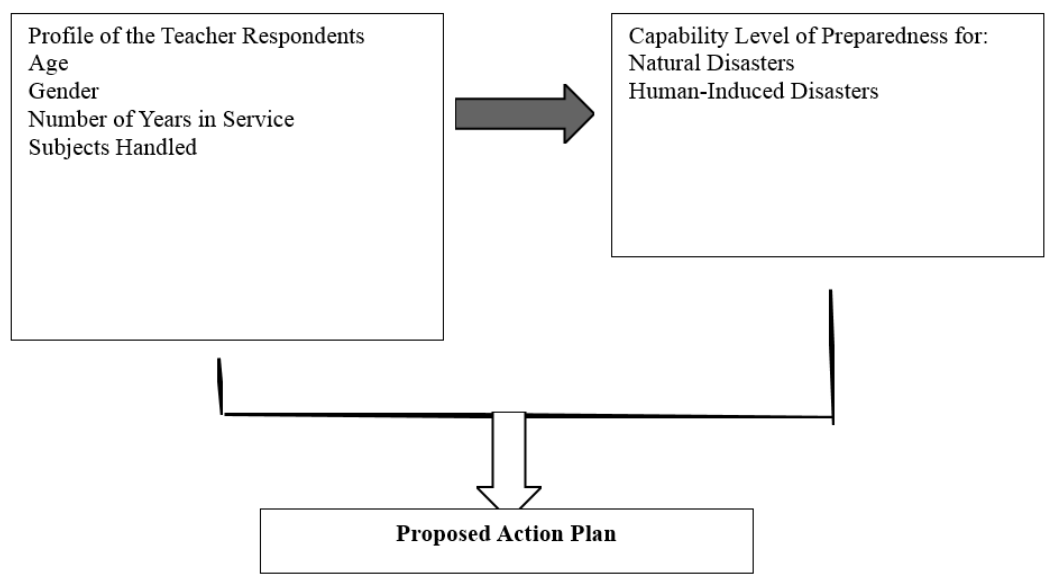

Figure 1. Research Paradigm

\subsection{Statement of the problem}

This study aims to propose an action plan that would address the gaps identified based on the capability level of the teachers to prepare for school-based natural and human-induced disasters. Specifically, this study 
conducted to answer the following questions: First, what is the profile of the respondents in terms of age, gender, numbers of years in service, and subjects handled? Next, what is the capability level of the teachers in school-based disaster preparedness in terms of awareness for natural disasters and human-induced disasters? Then, is there a significant difference in the capability level of teachers when grouped according to profile variables? Finally, is the relationship between the capability levels of teachers for preparedness for natural disasters and human-induced disasters, and based on the findings of the study, an action plan proposes to improve the disaster risk reduction and management in Sta. Teresita District?

Hypotheses - The first hypothesis tested is that there is no significant difference in the capability levels of the teachers on school-based disaster readiness when respondents grouped according to profile variables. Lastly, there is no relationship between the capability levels of teachers for natural disasters and human-induced disaster preparedness.

Significance of the Study - The results of this study will be of great significance to the following: First is the school administrators and supervisors, being the curriculum planners, revisiting the preparedness of teachers as regards disaster management would ensure informed decision-making. The blueprint in enhancing school managers' roles in managing disasters may help to minimize the negative impacts of disasters. Next are the teachers, where the result of the study will help inform the teachers on how well they fair in their role to give information to the students on what to do before, during, and after the disaster, thereby mitigating the destruction it could cause. Then the students, being at the center of the teaching and learning process, will be primary beneficiaries of effective disaster risk management. Raising their awareness would equate to increasing safety and ensuring their welfare and wellbeing. Finally, the future researcher can also gain insights from the result of this study. To give them more ideas or insights and to help not only the respondents but also the community. It will also develop their creative and critical thinking in brainstorming a new research topic related to this study.

\section{Related literature}

The report of the Journal on Rehabilitation Medicine (2011), emphasized the role of the World Health Organization Liaison Sub-Committee on Rehabilitation Disaster Relief (CRDR) of the International Society of Physical and Rehabilitation Medicine (ISPRM) in developing an enhanced physical rehabilitation relief response to a large scale natural disaster. The CRDR has started that disaster rehabilitation is an emerging subspecialty within physical and rehabilitation medicine (PRM). According to the United States Federal Emergency Management Agency (FEMA, 2013), schools may be seen as the ideal setting for the dissemination of risk-based educational programs. Most children can be seen as malleable and easily shaped and molded, and if given the proper preparedness skills, children can develop those skills and carry them into their adulthood. FEMA further asserts that helping children gain a realistic view of disasters is vital in ensuring their comprehension and a realistic view of disasters is vital in ensuring their comprehension and understanding when faced with a major disaster. Disaster education programs should work to integrate a more realistic perception of risks into their materials and curricula and therefore, it will result in increased awareness and knowledge of protective behaviors.

Disaster relief has been at the forefront for quite a long time, communities are increasingly looking at disaster risk reduction as the best solution to safeguard human lives and property. Scholars and policymakers are relying on disaster preparedness and resilience as strategies to ensure disaster risk reduction whilst the International Strategy for Disaster Reduction (ISDR) (2007) has indicated that disaster management education is vital if school children are to be prepared and resilient in the face of disasters. According to the UNESCO Director-General, Koichiro Matsuura (UNESCO 2007), anticipating, educating, and informing are important ways to reduce the risk as well as the deadly effect of disasters.

In recognition of the role that education should play in disaster risk reduction, the International Strategy for Disaster Reduction dedicated 2006 as a year for encouraging both the integration of disaster risk education in 
school curricula in countries vulnerable to natural hazards and the safe construction and renovation of school buildings to withstand natural hazards. Their campaign, called Disaster Risk Reduction Begins at School, was inaugurated in many countries, including South Africa. The National Disaster Management Framework (NMDF), introduced in South Africa in 2005, also made provision for disaster risk education to be included in the national curriculum.

Haimes (2012) also suggested that "anticipating and planning for emergent forced changes through disaster preparedness and other risk management actions will necessarily improve the resilience of the system. Furthermore, he also claimed that emergency preparedness requires planning for multiple decision-making perspectives. This planning includes factors such as human resources, technology, and policies; interface arrangements among agencies at all levels (readiness must involve the public and private sector, not only government and non-government organization); and interoperability and information sharing that transcend security, primarily services such as police, fire and emergency management services but also health and safety, transportation and critical utilities and infrastructures, among others (Haimes, 2012).

In line with this, Somers and Svara (2016) claimed that such plans must identify the duties and responsibilities of each local department during an emergency, including the role of elected officials. According to the authors above mentioned, the extent of emergency planning as well as the focus of such planning - often is dictated as much by the availability of intergovernmental transfers by local hazards and vulnerability assessments. Cox (2012) pointed out that disaster preparedness has to be analyzed along with alternative plans and courses of action to be followed if disasters occur.

\subsection{Local}

In so far as disaster is a concern, the Philippine Senate and the House of Representatives, legislated the RA No. 10121 which began and was held in Metro Manila, on Monday, the twenty-seventh day of July, two thousand nine. Republic Act No. 10121 is an act strengthening the Philippine disaster risk reduction and management system, providing for the national disaster risk reduction and management framework and institutionalizing the national disaster risk reduction and management plan, appropriating funds therefore and for other purposes.

The handbook of Carter (2008) entitled, Disaster Management: A Disaster Manager's Handbook, stated that disaster preparedness refers to measures that enable governments, organizations, communities, and individuals to respond rapidly and effectively to disaster situations. This entails the formulation and maintenance of counter-disaster plans, special provisions for emergency action, provision of warning systems, emergency communications, public education, and awareness and training programs. The earthquake can occur anywhere along the West Valley Fault, including Metro Manila. But a 7.2 magnitude earthquake can shake the ground even a hundred kilometers away, which means that it can shake the whole of Metro Manila and its surrounding provinces.

Solidum (2016) reiterates that weak, poorly designed, and poorly constructed buildings far from the earthquake fault are still vulnerable to destruction. Grounds can also be affected by liquefaction, a process where loose, sandy sediments behave like a liquid, Solidum explains. It becomes weak. This can cause poorly designed or constructed buildings and homes to subside or tilt, roads fissured, and water banks. Broken areas near the waters like Marikina Valley down to Manila de Bay, and the coastal cities of Metro Manila are also more likely to experience stronger ground shaking due to the softer ground they sit on.

As of June 19, 2013, the Department of Public Works and Highways reported about the Flood Management Master Plan for Metro Manila and Surrounding Areas. The report indicated that after the flood events brought about by typhoons Ondoy and Pepeng in September and October 2009, respectively, that caused severe damage in Metro Manila and surrounding areas, the World Bank has provided a technical grant for \$1.5 million under the Global Facility for Disaster Reduction and Recovery Trust Fund of the Australian Agency for International 
Development (AusAID).

Based on the report by Kim Luces of GMA News on July 10, 2013, he highlighted that the next big quake in Metro Manila may hit within our lifetime. He elucidated that earthquakes are impossible to predict but, based on historical records, Metro Manila's West Valley Fault is due for the Next Big One within our lifetimes. A possible 7.2 earthquake looms around the corner if the West Valley Fault along the eastern side of Metro Manila cracks, Renato Solidum Jr., Philippine Institute of Volcanology and Seismology (Phivolcs) director warns. The West Valley Fault that runs from the heights of Sierra Madre down to Laguna. It crosses the eastern side of Quezon City, the western side of Marikina, the western part of Pasig, the eastern part of Makati, parts of Taguig, and Muntinlupa. The fault has moved four times in the past 1,400 years. On average, it moves every 400 years, +/10 to 100 years, maybell, Solidum says. The last time an earthquake occurred along the West Valley fault was in 1658, around 355 years ago. It can happen within our generation or the next generation, Solidum said.

Preparation remains the best option, unlike storms and typhoons, earthquakes cannot be - forecasted\| and can only be predicted by looking at how often it happens in history. To date, there are no scientific instruments that predict when an earthquake will occur. Solidum said that the possibility of a movement from the West Valley Fault is more than enough reason for us to prepare for it as soon as we can. The most important preparation measure, Solidum said, is to make sure that buildings, houses, and infrastructures in Metro Manila are earthquake and fire-resistant. He also said that at the local level, the physical integrity of the buildings should be assessed. Major lifelines like water and power supply and communication means should be strengthened and made fire and earthquake-proof. Another is to have an efficient relief and recovery system after the earthquake. Solidum suggests a - Bayanihan" style of relief and recovery where provinces unaffected by the earthquake could help those that are unaffected. Preparedness need not only be concentrated in Metro Manila and the surrounding provinces, but also the other regions. First aid and rescue should be available in each community in case major assistance cannot immediately arrive in their area after an earthquake - TJD/OMG, GMA News.

Basic education and disaster prevention go hand in hand. The methods for recognizing and assessing the future impact of hazards, vulnerabilities, risks, and identifying strengths and capacities happen to contain the fundamentals of scientific thinking as well as the basics of good citizenship and participatory governance. The values, attitudes, and technologies needed for physical protection; informed planning, environmental stewardship, disaster-resilient design, and construction, are the same as those fundamental to sustainable development and livelihood security. The skills and provisions for disaster response are empowering and confer safety in everyday life. Disaster resilience is built upon a foundation of analytical and problem-solving skills and draws from the development of personal and interpersonal intelligence (Petal, 2008).

School safety and educational continuity require a dynamic, continuous process initiated by management and involving workers, students, parents, and the local community. School disaster management involves the following steps: assess hazards, vulnerabilities, capacities, and resources, plan and implement for physical risk reduction, maintenance of safe facilities, standard operating procedures and training for disaster response, test mitigation and preparedness plans and skills regularly, with realistic simulation drills (Pajaro, 2014). Disaster management in schools, as assumed by teachers as their role, plays a significant role in educating and developing the basic skill to face any disaster. Disaster management not only makes the students aware but also inculcates the right attitude to respond to the disasters. Training and capacity building enhances the ability of the students and school communities to make the right decision during an emergency. School students act as communicators/ mediators of the government to convey the recent policies, guidelines on prevention, and preparedness for disasters to the household communities. They are sensitized on different issues related to the disasters, causes, and effect, prevention, and preparedness practices as well as do's and don'ts of the disaster in the school through school curriculum, capacity building, and training by the use of demonstrations, mock drills, seminars and pamphlets (Trinidad, 2007).

Reducing disaster risks confronting the education sector is paramount to the achievement of the Department

98 Consortia Academia Publishing (A partner of Network of Professional Researchers and Educators) 
of Education's (DepEd) outcomes, namely: access, quality, and governance. As such, the Department, as a member of the National Disaster Risk Reduction and Management Council (NDRRMC), has been building the resilience of education by advancing school safety. By this thrust, DepEd has created the Comprehensive DRRM in Basic Education Framework, which underscores the following three pillars or areas of focus: 1) Safe Learning Facilities; 2) School Disaster Management; 3) DRR in Education. The ongoing implementation of these pillars is aligned with DepEd's commitment to the four thematic areas of the Philippine DRRM Act of 2010, otherwise known as RA 10121. These areas are Prevention and Mitigation, Preparedness, Response, Recovery, and Rehabilitation.

To enable focused, effective and strategic implementation, DepEd has established the office of the Disaster Risk Reduction and Management Service (DRRMS), with regular full-time staff in its central, regional, and division offices. The division offices are responsible for ensuring that schools have a functioning disaster management team (Luistro, 2014). The creation and upgrading of the DRRM service in DepEd (DO 50 s 2011 and DM 112 s 2015) institutionalized DRRM within the basic education system. Plantilla positions for DRRM Coordinators were created from national to division level offices to fully integrate DRRM policies and programs at all levels. Coordination and information management protocols, as well as roles and responsibilities, have been defined from school to regional levels to ensure coherence with the already existing structures and legal bases (DO 21 s 2015: DRRM Coordination and Information Management Protocol). Schools have established DRRM policies and programs in support of the national, regional, and division directions (RA 9155: Basic Education Governance Act of 2001). Specific interventions to address the effects of hazards and risks are determined at the school level. The School Planning Team (SPT) and the School DRRM Team (SDRRM Team) shall work hand in hand to implement DRRM. Within these two school groups assessment, planning, implementation, monitoring, evaluation, and reporting of DRRM interventions will be made.

\subsection{Foreign}

At some universities like Middle East Technical University (METU) and Istanbul Technical University (ITU), the centers of Disaster Management have been established. With the coordination of the Interior Ministry and the Technical University of Istanbul, some training was given to people and some other projects such as "Reconstruction of Fire Department" "Emergency Management Under the Conditions of Turkey" were initiated. Besides these projects, some conferences were organized by ITU and FEMA. A conference entitled "Good Governance and Disaster Management" was held by The Netherlands Municipality Union, and The Marmara and Straits Municipalities Union with the contribution of the Interior Ministry of Turkey in Ankara on 24-25 September 2011 (IM, 2011).

Several activities were initiated by METU among them the organization of Earthquake Disaster Mitigation Conference, Community Participation Sub-project, and some training efforts may be articulated (UNDP, 2012). Turkish Red Crescent societies and partners in the international Red Cross Movement, including the American Red Cross, have worked together to better prepare for the next crisis (Miller, 2011). The University of Bogazici Kandilli Observatory Earthquake Research Centre has initiated a training project for disaster preparedness. This project aims to raise the level of earthquake awareness and preparedness of the people (UBKOERC, 2012). There have been many projects held by local initiatives or joint ventures in Turkey. The International Union of Local Authorities (IULA) and East Mediterranean and Middle East Region (EMME) has launched a project entitled "Promotion and Development of Local Agenda 21s in Turkey" with the support of UNDP and Turkey. The objective of this project is to expand public awareness about disasters throughout the country (Local Agenda $21,2014)$.

The Ministry of National Education published a new circular in 2015 towards the implementation of a new curriculum in elementary schools. In this curriculum, some units have been added to some supplementary subjects related to disasters to enhance disaster awareness (MNE, 2015). Although several initiatives and studies have been put in use, they are not sufficient. The Government Bureau of Accounting has informed that especially 
for the prospective earthquake for Istanbul the preparedness efforts are not sufficient and not efficient as well (Hurriyet, 2013). The consequences of many types of research and the opinions of many people also denote that these efforts are not sufficient. The worst is that the cautions of many scientists, politicians, and other people related to the enhancement of awareness and preparedness levels for the catastrophes have not been taken into consideration by the key persons who hold the positions to make decisions (Isikara, 2013; Yilmaz, 2013).

In recent years, scientific studies have shown that school principals hold the number one position for the effective management of schools especially for realizing effective instruction, staff development, organizational learning, curriculum development, and building a school community together with the school environment. The school administration as an area of specialization is seen as requiring additional education and exceptional human relations and leadership qualities (BLS, 2011; Devos et al. 2018; del Castillo, 2021). Therefore, the principals through effective leadership may play a pivotal role in achieving a disaster-resistant culture in the schools. Especially, building awareness towards earthquakes and ensuring preparedness for prospective earthquakes together with the school environment, may lessen the destructive effects of the earthquakes in Turkey.

Synthesis - The above review of literature has shown that although there is information and recognition of the issues-related disaster management, there are very few studies done on the need assessment and preparedness of primary or secondary school teachers in the Philippines. The justification of the study was based on the fact that the safety of school children is a basic right of children. Teachers must be aware of disaster management in schools and gain knowledge and implement safety practices in the school environment. Hence, the researcher intends to assess the knowledge and capability of teachers in preparing for natural and human-induced disasters.

\section{Research methodology}

This segment of the study covers the research method used, respondents of the study, an instrument to be utilized, validity and reliability of the questionnaires, data gathering procedures, and the statistical treatment of the gathered data.

Research design - This study will make use of a descriptive quantitative research design to describe the characteristics of a population or phenomenon being studied. Descriptive research methods describe specific behavior as it occurs in the environment. In terms of designing the plan of action on the proposed plan to strengthen the school's disaster risk reduction and management, the researcher will follow three phases: the pre-development phase, development phase, and post-development phase. The pre-development phase includes the needs assessment, gathering of research literature and studies, development, validation, distribution, and interpretation of the research questionnaire. The development Phase covers the design of the proposed program and the final phase is the validation and revision of the program.

Instruments - Peer or inter-rater and an expert validation of the research instruments will be carefully executed in this study. Research questionnaires will be distributed to the teachers during their convenient time.

Data gathering procedure - The researcher will personally administer the questionnaire to the target respondents. To be able to do this, the permission of the School Administrators will be sought and consents from the target participants. When the permission is granted, the survey will commence. Questionnaires will be retrieved, then data collected, tallied, and interpreted. The confidentiality of the responses gathered from them will be guaranteed.

\section{Presentation, interpretation and analysis of data}

This chapter presents the results of the data gathered after appropriate statistical tools were applied. Likewise, it presents the analyses of significant findings, by the specific problems in the study supported by related literature and studies. Results were presented in tables, with the textual discussions and corresponding 
analyses immediately following each of the tables. The highest frequencies and significant results for each table are discussed.

\subsection{Respondents' background on disaster preparedness}

First aid training - Table 1.1 presents the frequency distribution of the respondents according to first aid training attended. Among the 82 teacher respondents, relatively low percentages were noted as regards the first aid training they attended. The highest frequencies of 10 and $9(12.20 \%$ and $10.98 \%)$ were accounted for by those who attended training on dressing and bandages and wound and bleeding, respectively. This could be explained that this training forms part of most of the activities of scouting.

\section{Table 1.1}

Frequency distribution according to first aid training attended

\begin{tabular}{lcc}
\hline \multicolumn{1}{c}{ Training } & Frequency & Percentage \\
\hline Burn & 6 & 7.31 \\
Wound and Bleeding & 9 & 10.98 \\
Dressing and Bandages & 10 & 12.20 \\
Poisoning & 0 & 0.00 \\
CPR & 6 & 7.31 \\
Fracture & 5 & 6.10 \\
Heart Attack & 0 & 0.00 \\
Shock & 0 & 0.00 \\
\hline
\end{tabular}

The results show that the majority of the teachers in Wenceslao Trinidad have not attended first aid training. This finding is similar to that of Napere and Canencia (2013) who found out that most of the teachers in Iligan City have no formal training on disaster preparedness.

Simulation exercises - Table 1.2 presents the frequency distribution of the respondents according to simulation exercises attended. Among the 82 teacher respondents, relatively high percentages were noted as regards attendance and participation in earthquake drills $(70=85.37 \%)$.

\section{Table 1.2}

Frequency distribution according to simulation exercises attended

\begin{tabular}{lcc}
\hline \multicolumn{1}{c}{ Simulation Exercises } & Frequency & Percentage \\
\hline Fire Drill & 25 & 30.49 \\
Earthquake Drill & 70 & 85.37 \\
Hazard Mapping & 6 & 7.32 \\
Life-Saving & 4 & 4.88 \\
\hline
\end{tabular}

Findings revealed that the majority of the respondents have received simulation exercises. This is favorably at a minimum of once every year coinciding with the reports by the Department of Education (2015) that all elementary and secondary school teachers and students are required to undergo disaster training in the form of drills. It also agrees with the findings of the study by UNICEF (2012) that school-based disaster programs in the Philippines would always include capability training of both school supervisors and teachers. Lastly, it complements a report by IRIN (2012) that public school teachers are trained by the National Disaster Risk and Management Council volunteers for disaster preparedness. Nonetheless, the number of respondents without disaster preparedness both as to training and simulation exercises $(11=13.41 \%)$ cannot be underestimated and must be given much attention and intervention.

\subsection{Capability level of the teachers in school-based disaster preparedness}

The capability levels of the respondents to prepare for school-based disasters are reflected in the DepEd Disaster Risk Reduction Resource Manual are presented.

Natural disasters - The composite mean values reflected in Table 2.1 represent the average responses made 
Dimaculangan, J.

by all participants to each natural disaster.

Table 2.1

Composite mean scores of the capability levels for natural disasters

\begin{tabular}{lcc}
\hline \multicolumn{1}{c}{ Disaster } & Composite Mean & Verbal Interpretation \\
\hline Typhoon & 3.32 & Extremely capable \\
Flash flood & 3.03 & Highly capable \\
Global Warming & 3.34 & Extremely capable \\
Earthquake & 3.09 & Highly capable \\
\hline
\end{tabular}

As shown in Table 2.1, the respondents agree that their capability levels for global warming and typhoons are extremely high with composite mean values of 3.34 and 3.32, respectively. However, on earthquake and flash flood, it was seen that the respondents regarded themselves as highly capable with lower composite mean values of 3.09 and 3.03 respectively. The results are positive as the composite mean values fall under highly and extremely capable. On the other hand, these findings agree with those of Napere and Canencia (2013) that teachers are capable enough to prepare and respond to the school-based disaster.

Human-induced disasters - As shown in Table 2.2, the respondents agree that they are highly capable of food poisoning and kidnapping with composite mean values of 3.07 and 2.77, respectively. However, on fire and chemical spill, it was seen that the respondents regarded themselves as moderately capable with the lower composite mean values of 2.50 and 2.52 respectively.

\section{Table 2.2}

Composite mean scores of the capability levels for human-induced disasters

\begin{tabular}{lcc}
\hline \multicolumn{1}{c}{ Disaster } & Composite Mean & Verbal Interpretation \\
\hline Fire & 2.50 & Moderately capable \\
Chemical Spill & 2.52 & Moderately capable \\
Food Poisoning & 3.07 & Highly capable \\
Kidnapping/ Bombing & 2.77 & Highly capable \\
\hline
\end{tabular}

The results are positive as the composite mean values fall under highly and moderately capable. This finding coincides with the results of the study by Dragon (2015) that teachers have average to high levels of knowledge and awareness to respond to disasters. Likewise, the results complement the study by Boyd (2011) that teachers have moderate to high levels of preparedness to respond to acts of violence in school.

\subsection{Difference in the capability level of teachers according to background}

Table 3.1 and 3.2 detail the association between frequencies of school-based disaster preparedness in terms of first aid training and simulation exercises attended by the teacher respondents. F and p- values as well as their corresponding verbal interpretations are presented on the tables.

Table 3.1

Differences in capability levels for school-based disasters based on first aid training

\begin{tabular}{lccc}
\hline \multicolumn{1}{c}{ Disaster } & & \multicolumn{2}{c}{ First Aid Training } \\
\hline Natural Disaster & F value & $p$-value & Verbal Interpretation \\
\hline Typhoon & 6.680 & .000 & Significant \\
Flash flood & 1.935 & .089 & Not significant \\
Global Warming & 2.439 & .035 & Significant \\
Earthquake & 2.983 & .012 & Significant \\
\hline Human-Induced & F value & $p$-value & Verbal Interpretation \\
\hline Fire & 5.456 & .000 & Significant \\
Chemical Spill & 2.338 & .042 & Significant \\
Food Poisoning & 4.277 & .001 & Significant \\
Kidnapping/ Bombing & 2.099 & .066 & Not significant \\
\hline
\end{tabular}

102 Consortia Academia Publishing (A partner of Network of Professional Researchers and Educators) 
Between the frequency of first aid training attended and natural hazard typhoons, the $f$ value is 6.680 , the $p$-value is .000 and the verbal interpretation is significant. In terms of first aid training and flash flood, 2.151 is the f-value and 0.60 is the $p$-value, with the interpretation being not significant. On global warming, there is a $2.439 \mathrm{f}$-value and a $0.35 p$-value interpreted as significant. As regards earthquake, 2.983 is the f-value while .012 is the $p$-value which is interpreted as significant.

Table 3.2

Differences in capability levels for school-based disasters based on simulation exercises

\begin{tabular}{lccc}
\hline \multicolumn{1}{c}{ Disaster } & \multicolumn{2}{c}{ Simulation Exercises } \\
\hline Natural Disaster & F value & $p$-value & Verbal Interpretation \\
\hline Typhoon & 3.105 & .010 & Significant \\
Flash flood & 2.151 & .060 & Not significant \\
Global Warming & 2.775 & .018 & Significant \\
Earthquake & 2.404 & .037 & Significant \\
\hline Human-Induced & F value & $p$-value & Verbal Interpretation \\
\hline Fire & 3.043 & .011 & Significant \\
Chemical Spill & 3.005 & .012 & Significant \\
Food Poisoning & 2.677 & .022 & Significant \\
Kidnapping/ Bombing & 1.915 & .066 & Not significant \\
\hline
\end{tabular}

In terms of first aid training attended and human-induced disaster- fire, the $\mathrm{f}$ value is 5.456 , the $p$-value is .000 and the verbal interpretation is significant. In terms of first aid training and chemical spill, 2.338 is the $\mathrm{f}$-value and .042 is the $p$-value, with the interpretation being significant. On food poisoning, there is a 4.277 f-value and a .001 p-value interpreted as significant. As regards earthquake, 2.099 is the f-value while .066 is the $p$-value which is interpreted as not significant.

Between the frequency of simulation exercises attended and natural hazard typhoons, the $\mathrm{f}$ value is 3.105 , the $p$-value is .010 and the verbal interpretation is significant. In terms of first aid training and flash flood, 2.151 is the f-value and 0.60 is the $p$-value, with the interpretation being not significant. On global warming, there is a $2.775 \mathrm{f}$-value and a $.018 p$-value interpreted as significant. As regards earthquake, 2.404 is the f-value while .037 is the $p$-value which is interpreted as significant.

In terms of simulation, exercises attended and human-induced disaster- fire, the f value is 3.043 , the $p$-value is .011 and the verbal interpretation is significant. In terms of first aid training and chemical spill, 3005 is the f-value and .012 is the $p$-value, with the interpretation being significant. On food poisoning, there is a 2.677 f-value and a .022 p-value interpreted as significant. As regards earthquake, 1.915 is the f-value while .066 is the $p$-value which is interpreted as not significant.

The results show that the majority of the differences in the capability levels when respondents are grouped according to the frequency of first aid training and simulation exercises attended by the participants are significant. The differences are significant in 6 disasters: typhoon, global warming, earthquake, fire, chemical spill, and food poisoning. The results seem to disagree with the study of Napere and Canencia (2013) that the presence of disaster training does not relate to the disaster knowledge among the teachers.

\subsection{Relationship between the capability levels of teachers on preparedness for natural disasters and human-induced disasters}

Table 4 below shows the relationship between the capability levels for natural disasters and human-induced disasters. Statistical tests showed that there is a significant correlation between them, $\mathrm{r}=0.667, p<0.05$. This finding suggests that as the capability level for natural disasters increases, the capability level for human-induced disasters also increases. 
Dimaculangan, J.

\section{Table 4}

The relationship between the capability of teachers for natural and human-induced disasters

\begin{tabular}{lcccc}
\hline \multicolumn{1}{c}{ Variables } & r value & $p$-value & Decision & Verbal Interpretation \\
\hline $\begin{array}{l}\text { Natural Disaster } \\
\text { Human Induced Disaster }\end{array}$ & 0.677 & 0.00 & Reject Hypothesis & Significant \\
\hline
\end{tabular}

The significant positive correlation that was seen connotes that the proposed plan of action that this study aspires to put forward, if adopted and properly implemented, will increase capability levels for both types of disasters.

\subsection{Proposed action plan}

The recommended training constructed based on the highlight results of the study include knowledge and capacity building on first aid not only on basic life support but must include trauma management and emergency response; simulation exercises have to be done and participated in more frequently; curriculum integration and lesson plan inclusion of topics, pedagogical strategies and activities focusing on raising disaster awareness and preparedness; active involvement of teachers from various disciplines and personnel to become members of disaster preparedness groups initiated by the different agencies; and implementation of various agencies.

The proposed training and activities, based on the results of the study, are put forward for the ultimate purpose of improving disaster preparedness in the school. This recommendation agrees with the findings by Guevarra, Ancheta, De la Pena, Ortega, and Lariosa that reinforcement of disaster preparedness training is necessary (as cited by Smart Schools Program, 2012). It also agrees with the study by Reyes, Diopenes, Co, and Berse (2011) because they stressed the importance of teacher training on disaster preparedness and the need for continuous professional development.

\section{Summary, conclusions and recommendations}

Disaster management is one important planning, responsibility and action to be considered not only by students but even teachers. About the Philippine schools' vulnerability to disasters, the study intends to evaluate the capability level of the teachers of Sta. Teresita District as regards their preparedness for school-based disaster. It needs to be understood more by the teachers for them to execute it well and even on how teachers would address different calamities and hazards that may happen in school and community.

\subsection{Findings}

Frequency distribution of the respondents according to first aid training attended - First among the 82 teacher respondents, relatively low percentages were noted as regards the first aid training they attended and among the 82 teacher respondents, relatively high percentages were noted as regards attendance and participation in earthquake drills $(70=85.37 \%)$.

Capability level of the teachers in school-based disaster preparedness - The respondents agree that their capability levels for global warming and typhoon are extremely high with composite mean values of 3.34 and 3.32, respectively. However, on earthquake and flashflood, it was seen that the respondents regarded themselves as highly capable with lower composite mean values of 3.09 and 3.03 respectively. Lastly, the respondents agree that they are highly capable of food poisoning and kidnapping with composite mean values of 3.07 and 2.77 , respectively. However, on fire and chemical spill, it was seen that the respondents regarded themselves as moderately capable with the lower composite mean values of 2.50 and 2.52 respectively.

Difference in the capability level of teachers according to background - Between the frequency of first aid training attended and natural hazard typhoon, the $\mathrm{f}$ value is 6.680 , the $p$-value is .000 and the verbal interpretation is significant. In terms of first aid training and flashflood, 2.151 is the f-value and 0.60 is the $p$-value, with the 
interpretation being not significant. On global warming, there is a $2.439 \mathrm{f}$-value and a $0.35 p$-value interpreted as significant. As regards earthquake, 2.983 is the $\mathrm{f}$-value while .012 is the $p$-value which is interpreted as significant.

In terms of first aid training attended and human-induced disaster- fire, the $\mathrm{f}$ value is 5.456 , the $p$-value is .000 and the verbal interpretation is significant. In terms of first aid training and chemical spill, 2.338 is the f-value and .042 is the $p$-value, with the interpretation being significant. On food poisoning, there is a 4.277 $\mathrm{f}$-value and a .001 $p$-value interpreted as significant. As regards earthquake, 2.099 is the $\mathrm{f}$-value while .066 is the $p$-value which is interpreted as not significant.

Between the frequency of simulation exercises attended and natural hazard typhoon, the $\mathrm{f}$ value is 3.105 , the $p$-value is .010 and the verbal interpretation is significant. In terms of first aid training and flashflood, 2.151 is the $\mathrm{f}$-value and 0.60 is the $p$-value, with the interpretation being not significant. On global warming, there is a $2.775 \mathrm{f}$-value and a $.018 \mathrm{p}$-value interpreted as significant. As regards earthquake, 2.404 is the $\mathrm{f}$-value while .037 is the $p$-value which is interpreted as significant.

In terms of simulation, exercises attended and human-induced disaster- fire, the f value is 3.043 , the $p$-value is .011 and the verbal interpretation is significant. In terms of first aid training and chemical spill, 3005 is the $\mathrm{f}$-value and .012 is the $p$-value, with the interpretation being significant. On food poisoning, there is a 2.677 $\mathrm{f}$-value and a $.022 p$-value interpreted as significant. As regards earthquake, 1.915 is the f-value while .066 is the $p$-value which is interpreted as not significant.

Relationship between the capability levels of teachers on preparedness for natural disasters and human-induced disasters - The statistical test showed that there is a significant correlation between them, $\mathrm{r}=$ $0.667, p<0.05$. This finding suggests that as the capability level for natural disasters increases, the capability level for human-induced disasters also increases.

Proposed action plan - The recommended training constructed based on the highlight results of the study include knowledge and capacity building on first aid not only on basic life support but must include trauma management and emergency response; simulation exercises have to be done and participated in more frequently; curriculum integration and lesson plan inclusion of topics, pedagogical strategies and activities focusing on raising disaster awareness and preparedness; active involvement of teachers from various disciplines and personnel to become members of disaster preparedness groups initiated by the different agencies; and implementation of various agencies.

\subsection{Conclusions}

The majority of the respondents have attended a limited number of first aid training and simulation exercises relative to disaster preparedness. Teachers are highly capable of preparing for natural disasters but moderately capable of human-induced disasters. The differences in capability levels are significant in 6 disasters: typhoon, global warming, earthquake, fire, chemical spill, and food poisoning. There is a significant positive correlation between capability levels for natural and human-induced disasters. Lastly, the recommended training and activities were constructed based on the highlight results of the study.

\subsection{Recommendations.}

Based on the aforementioned findings and conclusions, presented below are recommendations being proposed to improve the levels of disaster preparedness among the schools and their educators. In the school, it can likewise choose to measure the current capability for preparedness of students. Although the measure was achieved with the use of a validated questionnaire, the use of other effective measurement instruments may be employed. The principal, since the findings showed that there are moderate capability levels in some areas and there is a need for more training and simulation exercises, as the school manager, principal should craft actions that will improve the current levels of awareness and preparedness of the stakeholders. Lastly, the future 
Dimaculangan, J.

researcher, this paper primarily suggests the conduct of a similar study including respondents from other locales. That way, a clearer view of the capability levels for preparedness for educators may be established. Furthermore, the nature of this study might even be replicated among other schools in the different cities and municipalities of the country.

\section{References}

Alfred, J. (2011). The black earth: A compilation of essay on dark plasma theory. New Dawn Magazine. Arullo, R., \& Arullo, S. M. (2007). Pag-asa.

Beach, M. (2010). Disaster preparedness and management. Davis Company.

Carter, W. (2008). Disaster management: A disaster manager's handbook. Asian Development Bank.

Cunningham, W. P. (2008). Environmental science: A global concern (10th ed.). New York: McGraw-Hill. Datu, D. (2013). Fire incidents in Metro Manila rise by 13\%. ABSCBNnews.com/DZMM

del Castillo, F. (2021). Leadership: Towards equitable COVID-19 vaccination, Journal of Public Health, 43(2), 346-347. https://doi.org/10.1093/pubmed/fdab051

DOST Digest. (April, 2014). A monthly publication of the department of science and technology. Taguig City.

DPWH report. (June, 2013). Flood management master plan for Metro Manila and surrounding areas.

Federal Emergency Management Agency. (2013). Bringing youth preparedness education to the forefront: A literature review recommendation. USA: Citizens Preparedness Review.

Gosney, J., et al. (2011). Journal of Rehabilitation Medicine, 43(11). https://doi.org/10.2340/16501977-0890

Guevarra, J., et al. (2007). Assessment of disaster preparedness in selected public schools in Luzon. ActaMedica, $41(2), 78-84$.

Jacalne (2005). Emergency procedure during fire. Pamantasan ng Lungsod ng Muntinlupa.

Luces, K. (2013). The next big quake in Metro Manila may hit within our lifetime.

Pajaro, E. J., et al. (2014). Disaster awareness and preparedness of selected students of pamantasanng lungsod ng Muntinlupa. Muntinlupa City: PLMun-CTE.

Perez, R. T. (2007). Disaster preparedness through educational multi-media. PAGASA-DOST.

Republic Act No. 10121. (2010). Philippine disaster risk reduction and management act of 2010. Manila: Congress of the Philippines.

Trinidad, J. R. (2007). Exposure to natural disaster and environmental awareness and perception of environmental terms. UP-Diliman. 